\title{
The Implementation of Moral Damages Based on Calculated Exponential Injury Severity Score for Procedural Torts
}

\author{
Zharama Llarena \\ California Southern University, California, USA
}

\begin{abstract}
In this paper, the author aims to respond to the legal issues of procedural torts for violation of contracts and obligations in seek of quantification of damages. The universal civil rights entail several law topics and issues for civil cases pertaining to various measures for people, its human relations, obligations, and contracts corresponding to torts. Moral damages are qualitative issues being legally raised for indemnification of relevant ethical issues pertaining to behavior and reputation. Intentional and negligent torts through committed acts or omission may expose the suffered client at risk of emotional harm. Anger is an emotional trauma experienced by a person inflicted with external harm, such as discovered fraud and experienced injustice by an individual. Its management can exhibit the degree of trauma felt by a person. In this paper, means to measure the symptoms of aggressiveness brought by a series of recall by the individual is exhibited. Cognitive-behavioral intervention (CBI) was a tool used to mitigate post-traumatic symptoms brought by exposure risk to emotional harm. A 33-year-old Asian man had experienced moral injury to the extent of losing significant weight in a span of eight months resulting from being obese to a normal body mass index (BMI) as a result of his anger management. Exponential Injury Severity Score (EISS) in reference to Abbreviated Injury Scale (AIS) system showed that the 33-year-old Asian man had suffered severe injury with a score of 5.29 near to a 6.0 maximal score. Thus, the inflicted moral injury was exhibited to be severe, hence necessary compensatory damages should be provided to the plaintiff.
\end{abstract}

Keywords: human rights, human capabilities, torts, damages

\section{Problems on Civil Rights}

Global leaders, subsequent to the approaching end of World War II, had initiated a plan to banish war and resort in a sustainable harmony. The United Nations Charter envisions universal respect advocacy for, and regulation of, human rights and fundamental freedoms for all in equal treatments to race, sex, language, or religion as one of the approaches for the goal. The U.N. General Assembly applied and announced the Universal Declaration of Human Rights on the 10th of December, 1948. The first time Declaration spawned a common criterion of rights for all individuals and all countries in the absence of prejudice. Human rights are chiefly innate and natural, and its implementation, regulation, or utilization of human rights are bound to several issues. It is also a fact that without assurance to human rights, life development would lead to complicated problems. In this regard, each nation complies the international tool of human rights (Kamruzzaman \& Das, 2016).

Zharama Llarena, MS Phar Chem, Juris doctor student, former assistant professor and lecturer; Pharmacy Department, California Southern University, California, USA. 


\section{Concepts on Human Rights}

Rights are matters of what the population desires or demands towards their self-development. Rights are those fundamental criteria by which people cannot live in aversion to dignity. According to Hobbhouse, rights are what individuals demand from others and what other people desire from them in connection to a legal situational and beneficial agreement.

Human rights are those fundamental guidelines by which a population cannot live in diversion to dignity. The fundamental rights and freedoms, to which all people are endowed, often bound the provisions to the right to freedom of expression and thought, liberty and life, and equality before the law. To treat a person as if he or she was not a human being is to violate someone's human right. These are fundamentally few natural rights which cannot be violated, and at the same time cannot be assured by Statutory Law. It is the state obligation to protect and advocate human rights.

According to the description of the New Lexicon Webster's Dictionary of the English Language, human rights are expressed to be a freedom right from governmental violations of the person's integrity.

\section{Types of Human Rights}

Human rights are demands or desires covering a broad range of integrated rights. Grounded by 1948 Universal Declaration of Human Rights, civil and political rights, economic, social, and cultural rights, and solidarity rights are classified.

\section{Salient Features of Human Rights}

The substantial attributes of human rights make a variation from other rights. The novel characteristics are as follows:

1. Inherent: The chief outstanding attributes of human rights are that of which is natural and innate. Its acquisition is done without the use of any special quality of reputation, nor any charity of any individual or any social system. Every person by born is entitled to these rights.

2. Not exchangeable: Human rights are excessive demands or desires that are non-passable, non-exchangeable, or non-transferrable. It could be neither stolen, snatched, nor given away.

3. Universality: Universality protrudes as the fundamental value of human rights. Everyone is endowed to all the freedoms and rights proclaimed in this Declaration.

4. Equality: Human rights refer to equal utilization of resources and opportunities to all individuals. Indiscrimination, rule of law, and justice are the human rights philosophy.

5. Feasibility: The crucial features of human rights are its effectiveness or feasibility. Hence, human rights should never be perceived as an abstract or hypothetical idea. It is cultivated by social norms, culture, values, and institutions.

\section{Differences Between Human Rights and Fundamental Rights}

Human rights: Human rights are those fundamental guidelines by which people cannot live in aversion to dignity.

Fundamental rights: Fundamental rights are those human rights which are assured by the constitution.

All human rights are not fundamental rights but all fundamental rights are human rights. Human rights are focused with all people in the world but fundamental rights are associated between one state and its people. 
Historical perspective. The human rights concept is as old as the ancient natural right doctrine. It is ultimately generated subsequent to the human being creation. Hence, human rights are formulated day by day by the different treaty and declaration.

On the other hand, the fundamental rights are based from the human rights and acknowledged by the states' own constitution. State organization is preconditioned for assurance of fundamental rights but not important to human rights.

Universality. Human rights are equal demands for all individuals regardless of sex, race, and religion, or national or political origin. Human rights are universal, while fundamental rights are applicable only for a certain state population.

Protection and promotion. Human rights are advocated and protected by International Law but fundamental rights are restricted to the state constitution.

Enforcement. Although human rights are internationally acknowledged, it is implemented by the United Nations, International Laws, and other specialized organization. Since fundamental rights are implemented by the local judiciary, there are no alternative treatments against human rights violation but fundamental rights violation will be punished by the local judiciary.

\section{Human Rights and Capabilities}

In spite of the extensive appeal of the concept of human rights, it is also observed by many as being intellectually weak with lack in foundation and perhaps even in cogency and coherence. The significant co-existence of rousing appeal and deep ideal skepticism is not novel. The American Independent Declaration was observed through self-evidence that everyone is entitled by their creator with specific inalienable rights, and subsequent to 13 years, the French declaration of the "rights of man" confirmed that men are born and stay free with equal rights in 1789. Although it did not take Jeremy Bentham long to demand, in Anarchical Fallacies, published during 1791-1792, natural rights are basically without sense: imprescriptible and natural rights, rhetorical nonsense, and nonsense upon stilts (Sen, 2005).

The ideas of human rights and human capabilities consist of a common motivation, but they vary in several distinct means. It is beneficial to inquire whether there is a consideration of the combined two concepts, namely, capabilities and human rights, which can assist each idea to be understood and exercised into four specific questions. First, can human rights be observed as endowments to specific fundamental capabilities, and will this be a good means of rationalizing about human rights? Second, can the point of view of capability offer a comprehensive scope of the human rights content? Third, since human rights need certainty, does the utilization of the capability point of view for elucidation of human rights demand a full articulation of the list of capabilities? And lastly, how can we go about ascertainment of the content of human rights and of fundamental capabilities when our values should be quite divergent, especially across borders of community and nationality? Can we have anything like a universal method to these concepts, in a world where cultures vary and practical preoccupations are also of great difference?

Human rights as entitlements to capabilities. It is feasible to argue that human rights are best observed as rights to certain freedoms, and that the associated duties to consider the correlated obligation must also be focused around what others can do to protect and extend these freedoms. Since capabilities can be observed, widely, as freedoms of certain kinds, this would seem to establish a fundamental connection between the two conceptual categories. 
An argument can be raised between opportunity and process, which are two aspects of freedom that need distinction, with great significance of each deserving certain recognition. While the opportunity aspect of freedoms would seem to be placed to the same territory type as capabilities, it is not understood that the similar can be said about the process freedom aspect.

It is vital to acknowledge that both opportunities and processes can think powerfully in the human rights content. A due process rejection in being sentenced in the absence of a proper trial can be human rights infringements, and so can be the opportunity denial of medical treatment, or the living opportunity in the absence of being assaulted to danger.

The concept of capability can be very useful in understanding the opportunity freedom aspect and human rights. Certainly, although the opportunity concept is often cited, it does require considerable elaboration, and capability can aid in this elaboration. For an instance, perceiving the opportunity in terms of capability permits us to recognize appropriately between (i) whether an individual is actually capable to do things he/she would importantly do, and (ii) whether he/she possesses the ways or tools or allowances in pursuing what he/she would like to do. By diverging attention, for certain, towards the former, the capability-based approach refrains an overconcentration on ways that can be observed in some justice theories, like the Rawlsian Difference Principle. The capability approach can aid to determine the possibility that two persons can have various substantial opportunities even when they have exactly the same set of ways: For instance, a disabled individual can do far less than an able-bodied individual can, with exactly the same salary and other primary goods. The disabled person cannot, hence, be judged to be equally favored with the exact opportunities same as the individual in the absence of any physical handicap but with the same set of ways or tools.

The capability point of view permits individuals to take into responsibility the variability in determinants in association between the ways, on one hand, and actual opportunities, on the other. Variations in the capability to function can result even with the same set of personal ways for different reasons, such as: (1) heterogeneities in physical or mental among persons; (2) differences in non-personal resources; (3) environmental variations; or (4) varying relative positions facing other situations.

Several terrible starvations in the world have resulted from the absence of freedom to escape extreme poverty. Although inactivity and laziness had been classical themes in the old literature on destitution, people have been deprived and suffered due to absence of alternative possibilities. It is the poverty connection with unfreedom that brought Marx to argue vehemently for the urgency to substitute the circumstances domination and chance over persons by the people domination over circumstances and chance.

The freedom importance can be led out also by consideration of other kinds of issues that are also focused to human rights, in consideration of the freedom of immigrants to refrain their ancestral cultural lifestyles and customs. This intricate subject cannot be sufficiently evaluated in the absence of determining between doing and being free to do that matter. A strong argument can be formulated on the side of an immigrant's having the freedom to refrain her ancestral lifestyle, but this must not be observed as an argument on the side of his pursuit to ancestral lifestyle whether he opted to pursue it or not. The focus of this issue is the individual's freedom to opt on how he/she should live with the inclusion of the opportunity to aim ancestral norms and it cannot be transformed into an argument for that individual certainly in pursuit of those norms specifying alternatives that are irrespective of what he/she has. The capability importance, reflecting opportunities, is focused to this distinction. 
The process aspect of freedom and information pluralism. While the capability concept has recognized merit in the evaluation of the opportunity freedom aspect, it cannot possibly transact sufficiently with the freedom aspect, since capabilities are attributes of personal advantages, and has a weak implication of equity or fairness of the engaged processes, or about the citizens' freedom to use and invoke methods that are equitable.

The opposing point of views can be resulted with various types of illustrations. It is currently by now, equally well-established, given equal care; women are inclined to have a longer life span than men. If one was only focused with capabilities, and specifically with capability equality to live long, it would have been feasible to formulate an argument for giving men medical care than women to balance the natural masculine handicap. But giving women less medical care than men for the similar health problems would completely violate a crucial need of process equity, and it seems logical to argue, in cases of this type, that equity demands in process freedom could reasonably override a single-minded focus on the opportunity freedom aspect. While it is crucial to highlight the significance of the capability point of view in evaluating the substantive opportunities of various individuals, that reason does not, in any means, go against observing the significance also of the process freedom aspect in human rights theory or for that matter, in a justice theory.

A theory justice or more generally, a sufficient theory of normative social choice that has to be active both to the processes equality engaged and to the equity and substantive opportunities efficiency that individuals can utilize. In transaction with the latter, capability can indeed offer a very useful point of view, comparable to Rawlsian concentration on primary goods. But capability, in great difficulty, can serve as the only informational grounds for the other recognitions, associated to processes that should also be assisted in normative social choice theory.

In consideration of the various components of Rawls's justice theory, Rawls's justice first mechanism engages the liberty priority, and the first part of the second mechanism engages process fairness, through insisting that offices and positions be open to public. The cogency and force of these Rawlsian concerns can neither be disregarded nor be sufficiently intended via on the sole reliance of informational capabilities base.

Same informational base plurality has to be cited in transacting with the recognition multiplicity that forms the basis of human rights theory. Capabilities and the opportunity freedom aspect, crucial as they are, have to be supplemented by equal processes recognitions and the absence of violation of individual's right to cite and use them.

Public reasoning, cultural diversity and universality. Certainly, the public reasoning role in the creation and decision of human rights is extremely crucial to grasp. Any common plausibility that these ethical claims or their rejections have, on this theory, relied on their capability to flourish and survive when they meet unimpeded analysis and discussion. The claim force for a human right would be seriously weakened if it were feasible to see that they are unlikely to survive open public scrutiny. But in opposition to a generally provided reason for rejection and skepticism, the case for human rights cannot be ignored basically by determining to the feasibility that in socially and politically inhibiting regimes, which do not permit open public forum, several of these human rights are not taken for granted at all.

Open critical analysis is vital for dismissal as well as for defense. The fact is that monitoring of human rights violations and the procedure of naming and sharing can be so efficient in some indicated broad reach of public reasoning when information becomes unoccupied and ethical arguments are permitted rather than prevented. 
A notion in unpassable impediments between the values of varying norms has become apparent and risen again over 100 years, and their articulation is very powerful today. The remarkable novel claim and usually, of dominance, has often times come from Western values critics, differing from regional ethics champions, or religious or customs separatists. Although often times, the novel claim has come from Western particularists. One good instance is Samuel Huntington's demand that the "West was West long prior to modernization”, and his assertion that individualism sense and individual tradition of rights and liberties are novel among civilized groups. Comparatively, the historian of ideas is no less than Gertrude Himmelfarb that entered into conceptual argumentation of reason, right, justice and love of humanity are mainly, perhaps even novel Western values.

Variations on the topic of rights and freedoms are not the only current existing disparity between societies that are often much exaggerated, but also there is usually few points taken of remarkable differences within each local norm through time and even at a note of time. What are understood to be unfamiliar criticisms usually match to inherent criticisms from non-mainstream clusters. If Iranian opponents are accurately sequestered by an authoritarian government, it is due of their heterodoxy, any advice that they should be observed as Western values ambassadors rather than as Iranian opponents would only supplement a mock to exhibit injury. To be culturally non-partisan, it needs veneration to the involvement of society from any dimension of the earth, which is incomparable to accept the current priorities, especially among domineering clusters in specific groups, when details are extremely limited and forums and arguments are not allowed.

Analysis by far may have something to provide in the evaluation of practices as it varies from each other as the mockery of unfaithful women in the Taliban's Afghanistan and the abounding capital punishment utilization in some states of America. This is the type of problem that made Smith demand that the focus of the people must be cited to grasp whether a there is equity in punishment. Finally, the training of critical moral analysis needs, among other matters, achieving to perceive with the minds of other individuals, or as other individuals are similarly to perceive them.

Intellectual discussions across the borders can be as vital in wealthy clusters as they are in penniless ones. The issue to cite here is not so much there is permission to chat across borders and to do cross-boundary analysis, but that the training of critical evaluation of ethical sentiments, regardless of the degree of their local establishment, needs that the perception of practices correlates from a specific distance.

Grasping both human rights and sufficiency of a list of fundamental capabilities, an argument can be intimately raised in the association to meet public forum between people and across borders. The universality and viability of human rights and of an acceptable certainty of capabilities rely on their capacity for survival of open critical analysis in public reasoning.

\section{Importance of Human Rights Into Health Impact Assessment}

Health impact assessment (HIA) is continues to rise in utilization in a disparity of settings to forecast the health outcomes of the proposition of global and domestic policies, laws, and programs. There are many descriptions of HIA, although one broadly noted the explication that was discussed in the Gothenburg Consensus Paper: "Health impact assessment is a combined methods, procedures and tools by which a program, policy, or project may be evaluated as to its possible outcomes on the cluster health, and the spread of those outcomes within the group” (MacNaughton \& Forman, 2014).

Even though there are several descriptions, there is acceptable coherence among practitioners and scholars in explaining the fundamental components of HIA. First, it is broadly considered that HIA is expected, so as to 
explain the carrying out of future prediction outcomes and to update evaluations on treatments prior of undertaking rather than evaluation of impacts subsequent to an evaluation done and carried out. Second, there is global understanding on the procedural steps required to implement HIA. Third, involvement by stakeholders, who with potential is affected by the treatment and is also considered as a chief component of HIA practice. Certainly, more current descriptions of HIA are inclined to add involvement of stakeholders as HIA constitutive.

In spite consensus on these crucial attributes, there is no mutual understanding on the values and criteria facilitating HIA. This problem may have a reflection on the keen sources of HIA from three training communities, namely (1) environmental health, often linked with environmental impact assessment; (2) social health factors, concentrated on the underlying social variables of health conditions; and (3) health equity, concentrated on the varying outcomes of treatments on certain population clusters. While the environmental health point of view is guided toward health protection or prevention risks to health, the social factors and health equity concepts are harmonized with health promotion. Furthermore, in the keen concepts on the HIA purposes, there is a training boundary environmental health HIA grounded on toxicology and epidemiology, while the social factors and health equity HIA are majorly grounded in the social sciences with more qualitative information and highlight on involvement means.

\section{Legal Issues on Contracts and Obligations}

A contract serves as promise or set of promises that is bound to be legal. By legal binding, the law will enforce the individual doing the promise, the promisor, to do promise, or to indemnify the damages made, to pay the individual to whom it was done, the promise, for non-involvement. Promises are a usual attribute of our lives. People make promises to members of the family and their colleagues. Moreover, promises are done within the place of work, suppliers and their clients doing promises regarding the dissemination and claim of services and goods, and political groups do election promises. Although only a few of these promises are bound to be legal, only few of those are bound to be contracts. ${ }^{1}$

Contract law has no absolute descriptive theory that explains the meaning of law and it is not also an absolute normative theory, describing the expectations to law. These holes are expected provided the conventional contract description so as to embrace all promises of law enforcement. Even a contract law theory that emphasizes only on the bargains implementation, the entire continuum must still be considered from contracts of guidelines form between clients and firms to business contracts among commercialism. Contract law has not yet been explained in terms of descriptive theory that understands such a wide scope. Normative theories that are fundamental to a single custom, such as autonomy or effectivity, may also have been sourced over the heterogeneity of contractual backgrounds to which the theory is to be applied. Pluralist theories tend to answer to the complexity that unitary normative theories imply by enforcing courts to be in pursuit of fairness, efficiency, protection, and good faith of each autonomy (Schwartz \& Scott, 2003).

The proper contract law is the law system which the groups opt to choose, by implication and expression, the law facilitating their contract or, in the lack of such option, the law system with which the contract has its nearest and most real association. This common law tripartite hierarchy is conventionally observed constituting the following tiers: express option, inferred option, and objective option (Marshall, 2012).

${ }^{1}$ The Nature and Importance of Contract Law (Oxford: Oxford University Press). 
The assumption is usually done so as to be legally implementable, a promise should, at least, involve a moral obligation. Samuel Stoljar states that the need to maintain promises spawns in the moral sphere before walking into the legal phase. When a promise is done, the promisee holds a moral claim against the promisor, even though the former may not yet acquired the existing performance. Conrad Johnson stated that to be under a legal obligation is to be enforced a need for moral obligation. The legal obligation depicts the enforceable morality administration. The moral obligation to do contract occurs alongside the legal obligation (Al-Tawil, 2013).

In reference to this explication, the promisor is charged to two sets of obligations, such as moral and legal. Hence, when a judge, in the breach event, certainly implements the promised duty, they are in fact performing no more than enforcement of the promisor's moral obligation. The legal duty is extended to moral obligation. These are fundamental attributes of any legal system that is in step with the moral principles of promissory obligations. If common law should run to be equal to the morality of promises, it must announce the need for the breaching seller to maintain their promise, not to do basic indemnification of the buyer.

The policy that damages due to expectation, not particular performance, is the main intervention granted for contract breach, is usually acquired to exhibit that contract law does not acknowledge, and is not relied upon, a moral obligation to do a contract. This fact is in conflict with the moral perception that a contract is first and foremost a promise which hence, must be complied since a promise must be complied, although a promissory perception of contract law does not demand that particular performance be the default intervention. Despite of non-breaching party denial particular performance, the common contract law does not reject that the promise-breaker should have done the contract in the first place, and venerated their moral obligation, nor does it reject that particular performance is the standard and most appropriate moral answer to promise-breaking or anticipatory rejection. Yet, there are persuading reasons why the courts must not always, via legal ways, implement the morality of promissory obligation or particular performance. Contract law is grasped and can be stated to run neither in the opposition of promise morality nor the equivalent of it.

In common law, particular performance can only be available when there is insufficiency in damages. Several theorists have argued that the sufficiency test is an unsafe tool for explaining the reason behind contract law, if it certainly possesses that contractual obligation is grounded upon the moral obligation to maintain a promise, and does not routinely provide particular performance in the breach event. This aversion between legal dogma and the implication of a moral responsibility of promising is intensely deep as to be in demand of an explication. If the conventional perception that valid contractual obligations must be done is absolutely acknowledged in contract law, then does the reason behind the particular performance not routinely offered in the occasion of promise-breaking?

In reference to the common grasping of promissory obligation, judges must be in general take the contract moral force seriously as promises. They must be in the breach event, most often via legal ways of enforcement to morality of particular performance or promise. Once judges force the promisor in default to offer the promised performance, his moral obligation turns to be a legal obligation as well. The legal cultures for regulation of promises must not averse from the moral cultures that are applicable to them and the legal duty should be extended to moral obligation. It is therefore in enforceable representation of morality administration.

The failure to seriously acquire the moral force of agreements as promises is indicated that judges do not acknowledge a moral obligation to do a promise, and hence, run in the opposition of moral principles of 
promissory obligation. The moral obligation will not be in satisfaction if the promisor in default offers only an indemnification award.

The following question become apparent: Does the common law run in opposition of promise morality? Negative response is the reply to this inquiry. Several justifications have been raised to expound the common law's unwillingness to grant particular performance in spite indubitable acceptance as the suitable moral reply to promise-breaking.

The justifications in an attempt to obtain discernment for common law's method are not motivated on the basis of general normative position that opposes the importance of promissory cultures as utilitarian theories do. For an instance, an embrace to any implicit or explicit suggestion to beach a promise or inquire the contracting groups to apply the perception that people who break their contractual promises are making a good thing if this would result to improved social outcomes overall and that motivations should be generated for them to act in this means. Judge Oliver Wendell Holmes entered an argumentation that in law, a contracting group has the choice either to do the contract or to indemnify damages for the loss. Hence, a provision of compensation, no wrong will be committed and it would have done no more or less than to opt which means to do their obligation. Holmes perceived the obligation to do a contract as equivalent to an option to do or else to offer indemnification.

Holmes perception predates the termed effective breach theory. The concept on the theory basis states that the promisor should be permitted, or even motivated, to breach their contract and offer indemnification instead of pursuing a desirable or a more profitable venture than that which they are recently in pursuit, notwithstanding they have settled to a contract and acknowledged its terms. Lawyer-economists presume that an effectively broken contract benefits the social welfare, on the grounds that the breach will lead in a more effective utilization of services and goods. Hence, certainly persuaded by Holmes' grasp of contractual obligation as a basic choice either to do or to offer indemnification, lawyer-economists have scrutinized the contract law as a way to determine and reinforce effective economic attitude.

The common law's unwillingness to grant particular performance, in spite a certain acknowledgment that it is a suitable moral answer to promise-breaking, can be discerned on many sources. For an instance, it poses issues focusing both social cultures and the error risk; it generates a grave potential for opportunism; it is not needed in a contract demanding personal services since this may be equivalent to slavery, and in some instances, such as Co-operative Insurance Society Ltd. v Argyll Stores (Holdings) Ltd., is not required to do a demand that is undue to judicial supervision.

\section{Measures for Torts and Damages}

Tort law describes the situations under which an individual is endowed to damage indemnification if the claim is not grounded on a contractual obligation. Damages can be exhibited from property impairment or loss, limb or life, health, from the breach of rights or from pure non-financial or financial losses. In economics sense, every decline of an individual's utility level caused by an act of tort can be perceived as damage. Tort law policies have a goal of envisioning a fair and just boundary between those noxious occurrences that must result to damage indemnification and others for which the damage must be based where it falls. In Common Law countries, tort law has innovated from a large group of formerly unassociated dogmas such as nuisance, conversion, trespass, negligence, deceit, and defamation policies from case law (Schafer, 1999). 
In the discussion of law option for the determination of damages for torts, it is vital to recognize the difference between heads of damages and quantification of damages under those subjects. Heads of damages list the matters for which a jury or court may grant damages, such as lost wages, medical expenses, punitive damages, pain, and suffering. Quantification of damages gauges the proper amount under each permitted head, such as the indemnification measurement for pain and suffering (Weintraub, 2007).

It is also vital to concentrate on the definition of substantive and procedural as those terminologies are utilized for law option. For substantive problems, a court adopts the forum's choice-of-law policy to choose the appropriate law. Procedural in issues jargon is basically shorthand for stating the forum's policy adoption.

Procedural is a terminology utilized in several contexts. It may pertain to the policies that facilitate the mechanisms of the forum's courts, such as pleading, maintaining objections for appeal, and discovery. In the United States, it may pertain to a federal court's freedom to adopt a federal policy when the court has subject-matter jurisdiction due to the diversity of the groups for citizenship and is adopting state, not federal, law to substantive problems. On the other hand, as mentioned earlier, a procedural problem might be one for which the discussion court will not participate in its traditional choice-of-law scrutiny but will basically adopt its own policy.

Justice Frankfurter had stated:

Matters of substance and matters of procedure are much discussed about in the libraries as though they described a remarkable boundary prescinding across the whole scope of law. But, certainly, substance and procedure are the exact key concepts to extremely varying issues. Neither substance nor procedure depicts the same functions. Each has an implication of varying determinants relying upon the specific problem for which it is utilized. (2007, p. 2)

Hence, in evaluating for the adoption of the procedural label in the choice context of law, the question is: What justifies a discussion for insisting an application of its local policy when under the discussion's choice-of-law policy, the law of another legal territory application to all substantive problems? The proper criteria is one that neutralizes the complexity of rummage and application for the foreign policy in opposition of the likelihood for adoption of the forum's policy will influence the outcome in a method that will promote forum shopping. Pleading, serving process, maintaining objections for appeal, and comparable problems associating to the everyday activity of courts are properly named procedural for choice-of-law functions. Disregarding those policies will influence the result, but an attorney is unlikely to opt one discussion over another to take benefits of such housekeeping supplications. Discovery policies demand more justifications. A forum that allows substantial pre-trial evidences wouldbe similarly beneficial to plaintiffs. Discovery of U.S. style is one of the reasons that American discussions are attractions for the injured and aggrieved of the world. Nonetheless, it would be undesirable to demand U.S. lawyers and judges to adopt and learn foreign discovery policies. Discovery is properly termed procedural for choice-of-law functions.

How about damages? Heads of damages, the items that a jury or court may add for computation of the amount granted to the plaintiff, are universally recognized as substantive. If the discussion's choice-of-law policy for torts emphasizes to a Mexican state, Mexican state's law ascertains the heads of damages. Quantification of damages under these topics is recognized as procedural and discussion criteria adopt.

\section{Systematic Review of Literature}

Sound mental health and exercise are associated since exercise has the same principle with activity for the provision of opportunities for social participation, camaraderie, structure, companionship, concentrated 
awareness of the self in the current event, liberation of anger and aggression. It also hinders negativity on self-absorption and discouragement of withdrawal and isolation. To a certain degree, exercise can enhance memory, concentration, emotional expression, cognition, and interpersonal skills (Balcombe, 2012).

Sport involvement has been observed in some occurrences to be a psychological protective determinant in opposition to negative stress effects. Brown and Blanton discovered that students of both genders from a university involved in sports are unlikely to acknowledge or try suicide than their non-sporting counterparts. They generalized that team sports can offer a healing environment for people and aid in individuals to improve handling of emotional stress. Sport and exercise offers advantages for promotion of mental well-being of participants in several communities and is integrated to health promotion.

In determination for excellence, athletes have to adjust with tough programs for training, and participate well on the basis of regular competitions. Majority of elite team athletes perform in request of training and competition schedules, incorporated with season competition involving cycles to train, taper, and compete from every week until the next. Players from superior clubs may have supplemental commitments, such as matches and tournaments of inter-provincial league, or other cup competitions, for their country representation in international tournaments. The repetition and seemingly unyielding match fixtures, often in combination with travel stress, might motivate athletes beyond their psychological and physiological restrictions. Athletes move fast from one peak to the other point and, according to Kellman, he stated that the recovery phases result to short in today's restrictions of human activity (Venter, 2008).

Conventional means to train and compete have developed around work-based performance, including training challenges answered by basically performing more activities. Contemporary athletes are having more emotional, mental, and social needs everyday than ever before, including pressure on social relationships, sponsor demands, media needs, e-communications, more public interest, mobile phones, and information overload. Coaches and athletes are disputed to cite the redundant imbalance between recovery and stress, including the fundamental presumption, a greater performance load and increasing stress demanding augmenting recovery.

It is complex to look for a definite definition of explanation of athletic recovery, regeneration, or restoration in literature. The terminologies are often observed synonymous to athletes, coaches, and some authors pertaining to a vital element of athletic performance and a counterbalance to performance and non-performance stress. Hanin noted that training, such as underperformance in potential and expectations, can occur for varying reasons, but one of the usual reasons indicated for underperformance in excess of work with insufficient regeneration.

Kallus and Kellman described recovery or regeneration as an intra- and interindividual multi-level method in time for the re-establishment of training potentials. Recovery comprises an action-oriented element, and those volunteered trainings can be systematically utilized for optimization of situational circumstances and to construct and refill personal buffers and resources. It is, therefore, has an implication that active mechanisms are engaged with the goal to re-establish physiological, psychological, social, emotional, and behavioral elements that will permit the athlete to execute tax again on these resources. Recovery is described by Hanin as a volunteered and goal-driven performance with intentions determined to regain one's level of working potential reflected in an outmost pre- and mid- training state. Calder defined recovery as a common terminology utilized to define the physiological and psychological applications to workloads subsequent to an exposure of an athlete under competition or training. In reference to Calder, regeneration pertains to recovery of 
psychological attributes, specifically linked with mood states, while restoration pertains to the return of physiological markers to normal levels.

Recovery has tended to be a famous terminology amongst contemporary coaches and athletes, and it is usually grasped as a particular once-off procedure adopted subsequent to competition or performance session. Regeneration is a terminology utilized to highlight a holistic method, prioritizing the physiological, psychological, emotional, behavioral, and social stressors that should be applied to in the athletic context. Lamp and Benjamin pertained the entire athlete concept which stressed the fact that athletes convey the totality of their lives to their sports engagement, while Hassmen and Kentta (2002, p. 58) defined the athlete as a psychosociophysiological matter. Regeneration is associated to the definition of Kallus and Kellman (2001, p. 22) as intra and inter-individual multi-level method in time to re-establish training capabilities. Recovery is a term utilized based on a range of particular ways and processes or methods that can systematically be incorporated into the athlete's regime at several times to improve regeneration on varying levels, and associates to those volunteered performances that can be systematically utilized for optimization of situational occurrences and to construct and refill personal buffers and resources as defined by Kallus and Kellman (2001, p. 22), as cited previously. Recovery, hence, concentrates on the utilization of time between successive performance stimuli and sessions and adoptions of several methods to note fatigue determinants before another performance stimulus is incorporated. If the method is facilitated and adopted efficiently, overall regeneration of the athlete must be the outcome.

Athletic regeneration is thus an intricate and multidimensional method, which demands short- and longterm projection, and not just a concentration on restarting a system. It is also crucial that the athlete is informed in conditions of the demand for complete regeneration and the adoption of several recovery means to improve the regeneration method. Bompa suggested that, before utilizing recovery methods, the coach, psychologist, athlete, and medical employees should collaborate closely to prevent misinterpretations and maximize the efficiency of the athlete's regeneration via the particular methods adopted. The trainer, coach, physiotherapist, or other specialists collaborating athletes can guide the regeneration method, but it depends on the athlete whether to adopt several techniques away from the working context. The athlete demands to be authorized to do the correct options and be proactive in managing the regeneration method. The athlete is usually defined as being under-recovery state.

\section{Factors Associated With Regeneration}

Regeneration, as already mentioned, is a multidimensional method that relies on several extrinsic and intrinsic determinants. Stress, and the fatigue it inflicts to the athlete, should be grasped for efficient administration of several determinants. Even though several recovery processes are adopted to a team as a whole, it must be perceived that regeneration must be personalized in reference to the athlete's novel condition and demands.

Stress and fatigue. Gould and Weinberg defined stress as a crucial imbalance between a need in physical or psychological and response potential, under situations where unsuccessful meeting of needs has vital outcomes. Stress comprises of four interconnected phases. In the first phase of the method, some kind of need is positioned on the athlete. The second phase of the stress method is the athlete's concept of the demand. The third phase is the athlete's psychological and physical reply to the concept of the condition. If the athlete's notion of an imbalance between needs and response potentials inflicts the person to feel the threat, leading to an 
increase in state anxiety, resulting to an augmented worries, increased physiological activation, or both. Focus modifications, and muscle tension increment accompany augmented state anxiety. The fourth phase is the actual attitude of the athlete experiencing stress. It is, thus, vital for the professionals and coach collaborating with athletes to grasp the stress cycle. Apart from the determination and knowledge, the needs that are positioned on athletes, an evaluation must be done for those with experience or perception of stress in majority. Coaches must also grasp athletes' emotions and attitudes in terms of their reactions towards augmented stress. By grasping the stress cycle, particular efforts can be done for reduction and aid athletes to diminish stress.

Bompa noted that stress is a remarkable by-product of competition and training, with Gould and Weinberg noting that there are obviously many kinds of particular origins of stress. Stress is supplemented and generated amongst others by degree of training, competition, family, peers, spectators, and coach. Testing meetings and team options can also lead to stress. Smith stated that a significant body of evidence implies that elite athletes demand around 10 years of practice for acquisition of the required experience and skills to work at an international level. Athletes in reach of national and international levels have, thus, already made a lot of investments of personal time, have consumed several hours of activity, and have encountered various stressors engaged in competition level.

Fletcher, Hanton, and Coughlan investigated the quantity and content of organizational and competitive stressors in elite sport athletes. Competitive stress was defined as an ongoing deal between a person and the environmental needs linked chiefly and directly with competitive activity, while organizational stress highlighted on the interaction between a person and the sport committee. Ten international elite athletes, with mean age of 22 years, who were grouped under national squad and had engaged at the highest level, were studied. Five headings were determined, such as training problems linking to competitive stressors, and company stresses associating to environmental problems, individual cases, leadership problems, and team cases. Scrutiny disclosed that athletes reported closely four times as several company requirements than competitive requirements. Higher-order topics within the domain of training problems were preparation, injury, opponents, self, event, and superstitions. Higher-order topics within the environmental problems were selection, finances, training context, accommodation, competition context, and safety. Higher-order topics within the individual problems were nutrition, injury, and aims and desires. Leadership problems had the following higher-order topics, such as coaches and coaching styles. Team problems covered with company stressors relating to the group, such as cluster ambience, support network, roles, and communication.

Backhouse, Polman, Nicholls, and McKenna documented that professional rugby union players encounter a wide scope of sport and non-sport stressors. Outcomes from their investigation exhibited that the players encountered more stress on activity days comparing it to the rest or competition days. The authors also highlighted the demand for more notice to post-competition states so that athletes can be informed on varying intervention techniques they can apply to cite negative low-activated disagreeable states, which proved post-competition.

Principles that can cite the stressors and diminish the duration or the amplitude of fatigue must have an advantageous resulting change on the entire regeneration method. Several kinds of fatigue are noted, such as muscular, endocrine, metabolic (energy stores), neural, emotional, psychological, and social. Jeffreys advised that a grasp on the fatigue nature and the stress-associated determinants on players is a crucial step in setting up and facilitating a program for optimum regeneration. Fatigue cannot be observed as comprising a single cause. Stressors can source from several origins, all of which can aggregate into fatigue. Responses of players for 
activity loads will rely upon the total stress load and its mechanism associating their potential to facilitate the stressors. It is, thus, crucial that an interdisciplinary method must be noted to cite the individual demands of players. Suitable regeneration techniques and recovery processes must be executed continuously, usually in reference to varying time scales, relying on the contribution of each kind of stressor to entire fatigue.

Jeffreys stated that players' physical potentials are usually built progressively to permit them to manage huge loads, but their emotional and psychological potentials are often ignored. Psychological and emotional stressors can have a dramatic result on total stress and may, thus, negatively influence regeneration and the level of athletic activity. An entire regeneration technique must concentrate on citing all the dimensions for players to be maximally efficient. Players demand for development of their potentials resulting to identification and transaction with emotional and psychological stressors. Hassmen and Kentta suggested that a method to improve regeneration must try to attain a balance in the non-training and training stress encountered, the player's potential to adjust with the stress, and the recovery responses done.

Kellmann pertained to publications by the German researcher, Schonpflug, who noted that the player's responses to stress relied on permanent and consumptive supplies, which provided the player some stress resistance. The consumptive supplies pertain to recovery and regeneration, while permanent supplies pertained to the player's potentials and skills. Consumptive supplies supported and activated fixed resources. Restricted consumptive supplies, or replenishment failure, negatively influenced the regeneration of fixed supplies immediately. This subsequently augmented the risk of total supply exhaustion. Players must, thus, be motivated to generate, care for, utilize wisely, and substitute both origins to efficiently adjust with stress.

Individualizing the regeneration process. Kellmann cited that regeneration is particular to the individual. Players must have personal regeneration techniques, and also be provided several choices as for the mechanism for improvement to regeneration. They must be able to opt suitable techniques that they are relaxed with, that cite their regeneration demands and that are appropriate for a particular event. Jeffreys mentioned that this empowerment can also manage improved program compliance. Hanin pertained to investigations engaging players cross-country skiing, ice hockey, soccer, badminton, and squash, which clearly illustrated personal inclinations for regeneration techniques. Brukner, Sellwood, Nicol, Williams, and Hinman documented that, with all physical training, there is a psychological element that can improve activity, specifically in elite players who utilize several varying kinds of recovery techniques that do not comprise many empirical evidences behind them. What may be acknowledged advantageous by one player as a recovery strategy is not evidently of any advantage to another. Through time, players innovate their own recovery techniques that they utilize post-match and activity sessions. It is advised that the grasped psychological advantage of utilizing a similar recovery strategy might have a greater persuasion on training than perhaps the actual physiological advantage of that strategy.

Super compensation. Documents on regeneration will usually pertain to take measurements to manage supercompensation. It is advised that techniques are to be planned and processes executed with the goal of attaining supercompensation. Supercompensation happens when the overload breakdown activity and the following recovery are offset correctly while application and an overshoot in training happen. Bompa defined supercompensation as the association between regeneration and work as ground for psychological and physical arousal before a major match. It complies that the greater the activity load, the more recovery is demanded.

A supercompensation cycle can be explicated as follows: Subsequent to an exercise bout, the body encounters fatigue. In the event of non-training occasion, the biochemical stores are not only for replenishment, 
but surpass normal levels. The body counteracts fully, subsequent to rebounding or supercompensation phase, with a variable increment in player effectivity. When counteracting the breakdown method with the regeneration method correctly, an overshoot in activity potential, thus happens. It is highlighted that application of several systems happens during the regeneration phase. In reference to the supercompensation mechanism, more cogent activity stimuli would demand a longer recovery occasion. Bompa mentioned that psychological supercompensation demands longer than physiological supercompensation due to slower relaxation of nervous cell.

The training programme. Activity errors can negatively influence the player's training. Mistakes in the performance method of team players can constitute more than three hours of activity per day, more than a 30\% increment in activity load per week, neglecting the performance mechanism of easy and hard activity alternate days, no performance occurrence and corresponding regeneration microcycles, no rest periods, and excessively vast matches.

One of the activity errors often discussed is the absence of program planning in reference to the mechanisms of occurrence. Bompa explicated that occurrence has past sources and was utilized by Greek Olympians. The terminology sources from occurrence, which is a part or distribution of time into smaller, easy-to-handle partitions, termed activity phases. Occurrence of a yearly plan distributes the year into smaller activity phases, resulting to an easier plan and facilitates an activity program and assures peak training for major matches. The yearly activity cycle is partitioned into three major phases, such as preparatory, competitive, and transition, which distributed into smaller cycles. Smith defined occurrence as a planning method that makes the use of correct loads and sufficient regeneration for prohibiting fatigue in excess.

Planning in purpose for regeneration on micro- and macro- level, and the utilization of recovery strategies to aid the regeneration method to balance the competition and training stress, are thus, chief components of occurrence. Team sports have a sequence of matches scheduled in a two or three blocks of microcycles, which can lead in a high fatigue level. Regeneration microcycles must be particularly planned for especially complying a sequence of vital matches. Planning in reference to occurrence also permits for performance to alternate between days or sessions of low- and high-intensity performance, alternating between the energy taxed systems.

It is also crucial to plan for rest periods in the event of regular performance, in activity camps, and in the event of match phases, and particularly a rest from activity per week. Kentta and Hassmen attempted to encourage players to take a rest from activity per week by bonus points' allocation that can be supplemented to their recovery points garnered for the week.

Kellmann discussed that rest period in Germany is defined as a recovery holiday. It is not only important to plan for vacation time on a weekly reference, but players must also take longer events off from activity and match to deeply perform replenishment of their supplies. A weekend off can offer replenishment and regeneration to a particular degree, but it must not lead to substitution of a long-term vacation. Kellmann advised at least three weeks of break.

Verkhoshanky and Stiff (1993, p. 462) recapitulated what comprises an efficient activity program, which is a carefully contrived series of mental and physical stress in provided situational exercises, with one's situation being fixedly observed and restoration being planned in a means and at a rate suitable to current stress state. 


\section{Tool Intervention}

The influence of program design on fatigue. The supercompensation concept is the major straightforward representation of the performance application method. It is an idea that is established in the philosophy of almost all sports, coaches, and sports scientists accountable for the facilitation and planning of activity programs for elite players. The idea possesses that whenever a player is assigned to an overloading activity stimulus that causes strain or fatigue, the body will re-order its potentials such that the subsequent exposure to the same stimulus will generate less strain, provided that adequate regeneration or recovery relies chiefly on the degree of the initial overload and following substitution in homeostasis. To aim for attainment of supercompensation in activity, conventional activity theory suggests that each novel performance stimulus must begin until it perturbates from the recent activity regarding what has been completely restored or over-restored. Figure 1 exhibits this method, illustrating adequate recovery between following exposures to an activity stimulus. Since the exposure to the subsequent activity stimulus happens when the maximum activity effect from the recent session has been acquired, continual enhancements are attained. This is duplicated per session so that succeeding exposures in repetition lead in an aggregated positive activity effect (Taylor, 2012).

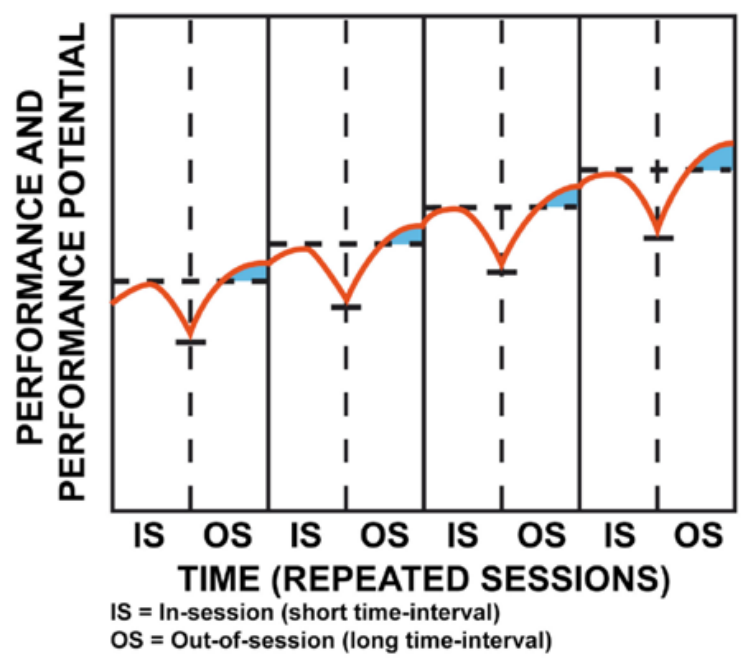

Figure 1. Stylized presentation of the responses to successive training stimuli when sufficient recovery between exposures is provided (adapted from Rushall \& Pyke, 1990, p. 33).

There is a restriction on the enhancement degree of players using this method. More current recommendations and theories support that physical loads must be repeated in organized manner in the absence of full restoration permit of homeostasis. This results to an aggregation of the immediate activity effects whereby the supplemental post-fatigue effects superimpose current ones, intensifying insufficient application. This method of inducement for fatigue valley, where stress aggregates over occurrences of days or weeks, demands heedful planning of the activity program. Continual evaluation of personal replies to the load turns even more substantial, since there is a crucial topic or reserve for each player where their threshold potentials cannot adjust with the aggregated fatigue. If this reserve is exceeded, incorrect application to activity can happen, leading in continual activity decline and overtraining state see (Figure 2). Prohibiting the maladaptation event, an optimal activity program demands to observe/evaluate the personal player's existing stress or fatigue tolerance. 


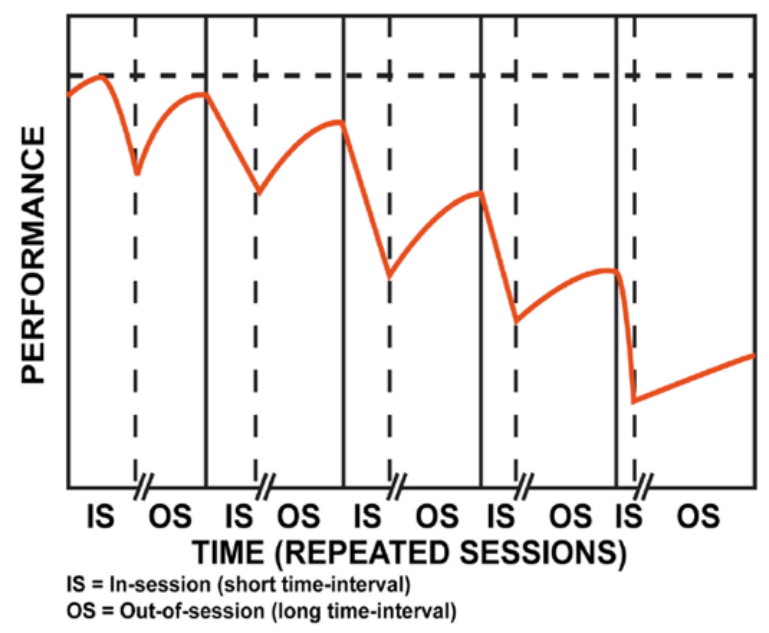

Figure 2. Stylized presentation of the responses to successive training stimuli when insufficient recovery between exposures is provided (adapted from Rushall \& Pyke, 1990, p. 34).

The balance of stress and recovery. The overtraining prohibition and optimal activity attainment can only be acknowledged when players are capable to do recovery and maximum balance performance stress and next recovery. When volume and intensity are augmented in the event of activity, subjective evaluation of players turns very crucial, due to a long-term stress imbalance and recovery can result to an overtraining state. Thus, it is suggested that recovery and stress be continuously observed in the event of the activity procedure. Norris and Smith list several performance mistakes that can result to overtraining. However, overtraining is not only because of performance mistakes but also a high frequency of competitive occurrences that do not permit for adequate recovery time. For underrecovery inhibition, recognized precursor to precursor, psychological and physiological recovery must be an integrated portion of the performance plan (Kellman, 2010).

In theory, an activity or performance load outcomes in fatigue degree subsequent to a supercompensation or performance effect. It is perceived that if the rest intervals between consecutive trainings are of maximal duration of the subsequent session will tally with the supercompensation level and the training ability will augment. A crucial clinical attribute of attribute is the augmented vulnerability to infections with equivalent symptoms, recommending immune response impairment.

Recovery. Coaches and players demand to be informed about the significance of maximal recovery and its potential result on training. Kellmann and Kallus have documented general recovery attributes establishment. The vital defining characteristics are:

- Recovery is a procedure in time and is relied on the kind and stress duration;

- Recovery relies on stress decline, stress change, or a stress break;

- Recovery is particular to the person and relies on personal evaluation;

- Recovery can be passive, active, or pro-active;

- Recovery is nearly bound to conditional situations.

Therefore, Kallus and Kellmann described recovery as an intra- and inter- individual multi-phase method in time for activity capabilities re-establishment. Recovery comprises an action-oriented element, and those volunteered performances can be systematically utilized for optimization of conditional situations and construction and replenishment of individual supplies and buffers. 
Interrelation of stress-states and recovery demands. In this discussion, Kellmann has done a general concept proposal that defines the inter-association between recovery needs and stress-states see (Figure 3). The central principle of this concept is that augmented recovery should happen simultaneously with the augmenting stress if the stress-state is to continue to be stable. If this does not happen, a negative cycle can lead if supplies are restricted, whereby augmented stress combined with being unable to meet augmented recovery needs outcomes in a personal experience leading to more stress. Recovery needs are described as the quantity and/or quality recovery performances demanded to balance the stress-state. People can become overpowered by stress and as a result, be incapable to look or make time for appropriate recovery or application more efficient techniques for adjusting with the condition.

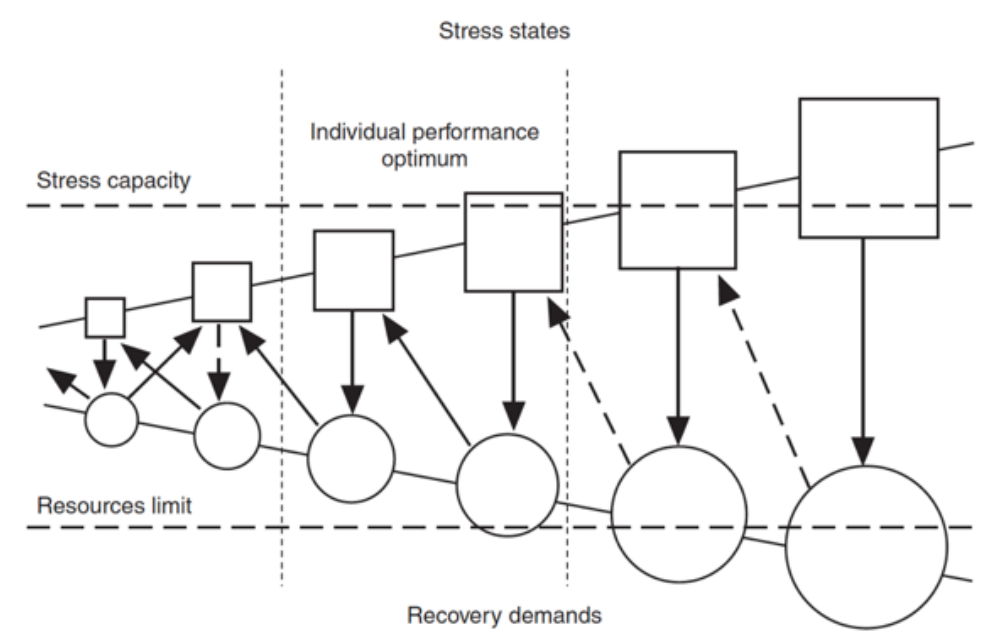

Figure 3. The "scissors-model" of the interrelation of stress-states, and recovery demands (Reprinted, by permission, from Kallus and Kellmann, 2000).

The concept further debates that with intermediate stress phases, individuals can attain a maximum training phase via sufficient recovery. In the event of stress phases further increased, individuals may lead to inability to meet recovery needs if they do not participate in supplemental recovery performances. As a result, stress will aggregate and in the absence of treatment, the overtraining symptoms are similarly to occur. Maximum training is related with recovery phases and balanced stress. If recovery is insufficient, the person can respond efficiently and successfully adjust with stress in the absence extra-recovery performances. In the absence of recovery, or underrecovery, it can volunteer a method that leads in a heightened stress state. In order to proceed for a re-establishment of a maximum training phase, players must be given with special benefits for recovery, as the augmenting stress can restrict the potential of people to recovery.

The concept can be adopted to sports to explicate the overtraining development. Stress-states happen on a continuum of augmenting performance load, with endpoints of no activity and overactivity. Organismic recovery needs are demanded to equivalent extended performance loads. By adding recovery into performance schedules, chronic training is improved. However, if heights in activity loads and intensity persistently augment through time in the absence of sufficient recovery, underrecovery is similarly to happen, which can eventually lead in the syndrome of overactivity. Subsequently, to attain the maximum recovery-stress phase, players must volunteer recovery performances to balance stress levels. Recovery variables as a regulation principle at every phase of the concept, by augmenting the distance between the two axes into a heightened recovery debt. The 
further a person develops along the stress-state, or the more overactivity happens, augments in recovery attempts are also demanded for a maximum recovery-stress phase to happen. Due to the regulatory recovery variable, the concept suggests that augmented stress phases are only harmful if the individual does not participate in sufficient recovery.

Rowing. Rowing demands players to be in good physical situation and to hold cogent motor skills because of its cyclic nature, including motions being done over and over in repetition. This sport demands an intermediate potential for high-intensity loads, endurance, and physiological variation, specifically incorporating an intermediate rowing time within 5 minutes, 20 seconds, and 8 minutes, relying on the boat type. Strength, flexibility, and endurance are especially crucial in rowing and respond in an intricate means.

Rowing is a performance-intensive sport, whereby performance constitutes of intricate programs that should be fully prepared and closely observed. Furthermore, in actual on-water sessions, activity includes gymnastic plays, power and strength endurance exercises, and workouts to enhance player's velocity and agility. Elite rowers perform within 10 and 14 times each week, with a further heightened sessions frequency in activity camps. Even at junior stages (16-18 years of age), activity camps for the World Championships are more than double the activity time than at home performance. Players apply in variation to heightened performance loads; some are capable to adjust and others are not. The augmented activity load impact is worsened if adequate recovery does not happen, such as lack of sleep. Subsequently, the intense quality of rowing activity makes these players especially susceptible to encountering underrecovery and emphasizes the demand for sufficient recovery observing tools.

Monitoring instruments. The Profile of Mood States (POMS) offers a self-evaluation for affective and mood levels, and is often utilized in psychological observance of activity/overactivity/underactivity. The POMS is a 65-item questionnaire in which answers are measured on a Likert scale of four (extremely) to one (not at all). The POMS offers a measurement for six mood phases and total mood disturbances (tension, depression, anger, vigour, fatigue, and confusion). The POMS is utilized for detection of mood fluctuations in workout and seems to gauge mood sub-elements, which are variably responsive to varying attributes of workout settings. It also offers an easy evaluation of the early signs of overactivity in players. However, the POMS does not offer details about the overactivity causes.

The Borg's Measurement of Perceived Exertion has also been utilized in a sport disparity and activity settings to gauge the exertion level grasped by a person. There is a well-grounded association between perceived exertion and activity load, and the RPE offers an accurate estimation of the activity stimulus intensity. More particularly, measurements of perceived exertion have been discovered to be a sound signal of application to activity programs engaging normal populations and hypertensive and cardiac patients.

More currently, Kentta and Hassmen have incorporated Total Quality Recovery, which tries to emphasize the association between recovery and training. Organized in comparison to RPE, this novel method is an efficient way of citing the issue of evaluating both underrecovery and recovery. Another method well-defined by Hanin, offers that players have a maximal functioning zone in which activity is optimized when a person's subjective, emotional encounter falls within this domain. Subsequently, the Individual Zones of Optimal Functioning (IZOF) offer a personal tailored conceptual design and toolset that tries to define, explicate, and predict the means in which maximal and dysfunctional levels can persuade a player's activity. IZOF has been further extended to comprise idiosyncratic emotion indicators of maximal and dysfunctional activity levels. 
These indicators are debated to offer an adequate and optimized criterion for recovery methods. Moreover, IZOF also suggest that personal optimal recovery techniques utilized by players must be recognized.

\section{Results and Discussion}

Monitoring instruments are important to assess the individual's mood, their need for recovery, and current life circumstances. The advantage of psychometric instruments is that they provide information quickly. While common physiological monitoring (e.g., blood analysis and/or specific medical/physiological diagnostics) may take hours or up to days for feedback, psychological data can be available within minutes.

The recovery-stress questionnaire for athletes (RESTQ-Sport) description. The RESTQ-Sport systematically evaluates the recovery-stress level of a player. The recovery-stress level illustrates the degree to which a person is mentally and/or physically stressed, and whether or not the individual is able of utilizing personal techniques for recovery. The RESTQ-Sport also evaluates the degree to which these techniques are currently being utilized with a Likert-type scale gauging the degree to which the participant accepted his role in varying trainings during the past three days/nights.

The RESTQ-Sport comprises of 77 items, which the respondents reply retrospectively. A Likert-type scale is utilized with values ranging from six (always) to zero (never) showing the frequency of the participant in answering different trainings within the past three days/nights. High scores in the stress-related performance scales show equivalent intense subjective stress, whereas high scores in the recovery-oriented measurements reflect good recovery trainings.

The RESTQ-Sport comprises of seven general stress measurements (general stress, emotional stress, social stress, conflicts/pressure, fatigue, lack of energy, and physical complaints), five general recovery measurements (success, social recovery, physical recovery, general well-being, and sleep quality), three sport-particular stress measurements (disturbed breaks, emotional exhaustion, and injury), and four sport-particular recovery measurements scales (being in shape, personal accomplishment, self-efficacy, and self-regulation). It also recognizes that the recovery-stress situation is an interim phase that constitutes physical, emotional, and behavioral attributes with a fixed and stable persistence.

Kallus exhibited that subsequent to 24 hours, the test-retest reliability of all general measurements is high (0.79), which illustrates that intra-personal differences in the recovery-stress levels can be gauged. High test-retest consistency exhibits firm outcomes in relation with short-term movements of recovery-stress level and functionary fluctuations. Recovery and stress in reference to Intercorrelations and Mechanism Element Analysis of the scales, must be observed to some degree, as independent elements. This allows data scrutiny in reference to personal measurements and on the determinants of recovery and stress.

Monitoring of the recovery-stress state. The RESTQ-Sport has been utilized in different sports and nations to observe players and the activity impact in the event of preparation camp for Olympic Games and World Championships. Assessment of the instrument utilization has discovered that differentials in performance volume were indicated by significant differences in RESTQ-Sport measurements. Particularly in rowing, it was discovered heights in activity volume which were indicated in augmented stress and diminished recovery scores gauged by the RESTQ-Sport. Gunther and Kellaman and Kellaman et al. documented significant increments in stress and diminishes in recovery when activity load expands, and vice versa. Variations in mood, creatine kinase (CK), and ergometer activity indicated the modification and performance success. Moreover to this data, Kellmann documented the equivalent progress through time of some 
RESTQ-Sport and POMS measurements over the testing event, which also recommends that both questionnaires seem to be responsive to occurrences in life of players that influence the recovery-stress level and mood, respectively. A cluster of Estonian scientists documented a sequence of investigations in rowing validating the previously defined association.

For rowers, Steinacker et al. and Steinacker et al. documented an association within hormone attributes and RESTQ-Sport outcomes. Physical complaints, as documented in the RESTQ-Sport, are highest in the event of most intensive performance level and associate it with augmented CK and cortisol. If physical complaints are reduced, CK and cortisol distribution also diminishes. In the same means, the norepinephrine peak amount matches to fatigue.

As illustrated in Figure 4, the RESTQ-Sport data can also utilized to assess activity programs in the off-season to recognize if the activity had the planned effects on the players. Moreover, in association to activity programs that scope many years, RESTQ-Sport data can offer evaluation to assess whether performance results met formerly established aims. Figure 4 illustrates variations in male rowers on the measurement being in shape in the event of activity camp that had duration of three years. It can be observed that the RESTQ-Sport results were responsive to alterations in the activity schedule throughout the program course. In an instance, variations to the 1998 activity camp to comprise high-impact weight lifting activity were indicated in variations in the RESTQ-Sport results.

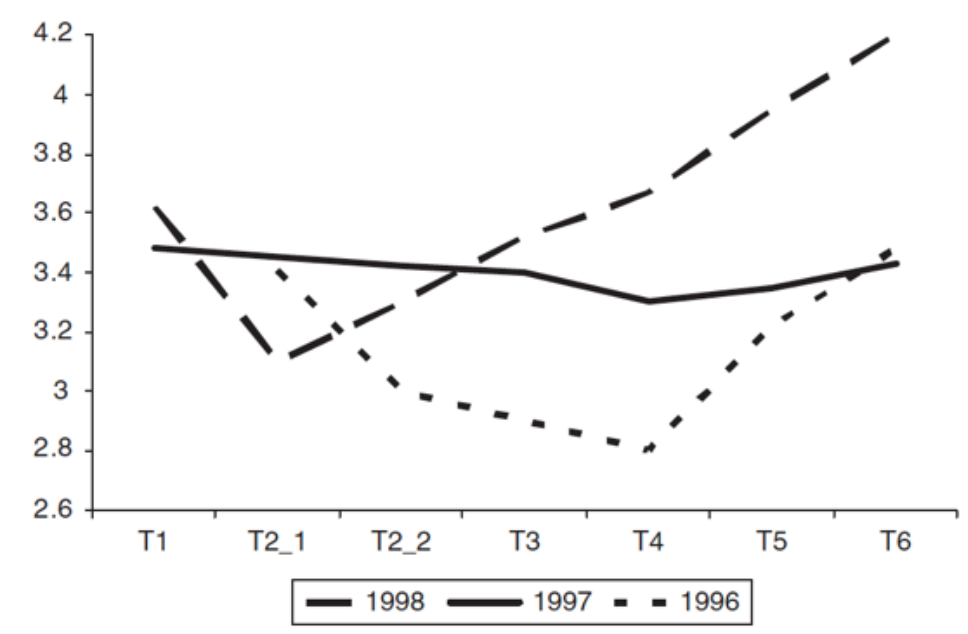

Figure 4. Arithmetic mean of the Recovery-Stress Questionnaire for Athletes Scale being in shape ( $0=$ never; $6=$ always) over three years for male rowers during the training camp before the Junior World Championships in Rowing. Whereas five measurements were taken in 1996 (T2_1, T2_2, T4, T5, T6) and 1997 (T1, T3, T4, T5, T6), six were used in 1998 (T1, T2_1, T3, T4, T5, T6). To compare the data, the assessments were adapted to the time schedule that describes the development over three years.

Figure 5 also offers evidence that the RESTQ-Sport is responsive to variations throughout the activity event. It illustrates differences in measurement scores for 17 males and females German Junior Rowers (5-17 years of mean age) who finished the RESTQ-Sport throughout the season course in 2000. Particularly, they finished the RESTQ-Sport six times over an interval of 24 weeks. As predicted, results on conflicts/pressure augmented throughout the phase of preparation and over the season, peaking prior the German Junior Championships, whereas results on fatigue diminished again from Week 23 to Week 24, while pressure/conflicts augmented throughout the season peaking prior the German Championships, just like 
self-evaluation. Players experienced physically and psychologically best at the regular season end, which was indicated by the results of being in shape. These scores highlight the significance of assessment of multiple recovery and stress elements. Since recovery is a method that is grounded upon personal preferences and potentials, recovery and stress must be continuously observed in the event of activity procedure to recognize which procedure aspect is most responsive to the personal condition of the player.

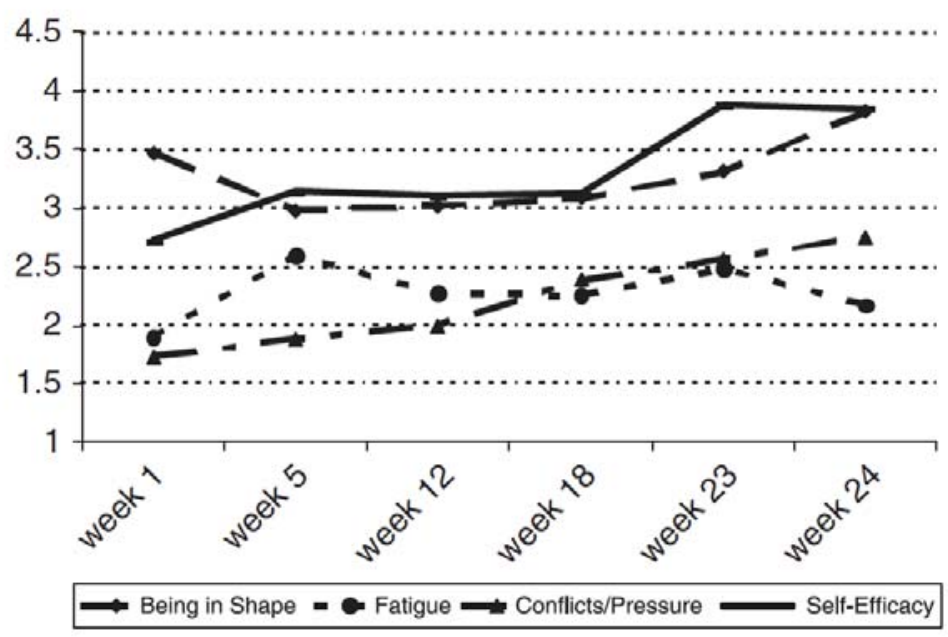

Figure 5. Comparison of the Recovery-Stress Questionnaire for Athletes Scales being in shape, fatigue, conflicts/pressure, and self-efficacy ( 0 = never; 6 = always) in the course of the season 2000 of German Junior Rowers (mean of 17 rowers).

Individual assessment. The following case exhibits further the adopted purpose of the RESTQ-Sport. The chief utility of personal evaluation is to recognize players whose recovery-stress levels do not produce equivalent activity schedule. Via early treatment, personal activity can be applied in order to assist the player transact with activity stress, optimize recovery, and subsequently inhibit overactivity. In a broad sense, it must be cited that low results in the stress-associated dimensions and high results in the recovery-associated dimensions are positively named, and vice versa. Although, in this literary background, terminologies, such as bad/good or negative/bad do not occur. It must always be hoarded in mind that the RESTQ-Sport profile indicates just one short event in an individual's life, which may modify extremely in the span of few days. Moreover, due to the recovery-stress phase is influenced by the existing activity schedule, the RESTQ-Sport scores interpretation must always be in regard with the existing activity phase.

Figure 6 illustrates two RESTQ-Sport profiles of a rower in 26 years of age. He finished the RESTQ-Sport two days prior and three days subsequent to a regular season regatta. At the first measurement, the pattern can be explained generally as peaking on stress and low on recovery, as well as in the sport-particular measurements. High results in lack of energy, fatigue, injury, and physical complaints are accompanied by low results for being in shape and physical recovery, illustrating a poorly balanced physical recovery-stress level or phase because of high-activity load or high-activity intensity. Furthermore, augmented results on the stress-associated measurements, such as social stress, emotional stress, general stress, and pressure/conflicts in supplement of low results on social recovery, success, and general well-being reflect that it was not only activity that was influencing this player when the questionnaire was finished. The coach dealt with the rower and offered assessment on the RESTQ-Sport profile. In the evaluation and communication, the player revealed 
the event of a problematic individual condition to the coach. Discussing with the coach assisted him to cite the issue and negotiate with his individual problems. Afterwards, at the second measurement, the RESTQ-Sport profile varied distinctly. General and sport-particular recovery augmented, while the other stress-associated measurements diminished, in exception of pressure/conflicts. This dramatic variation in results offers encouragement that the RESTQ-Sport profile indicates an individual's life momentarily, and has the capacity to extremely vary during a short time period.

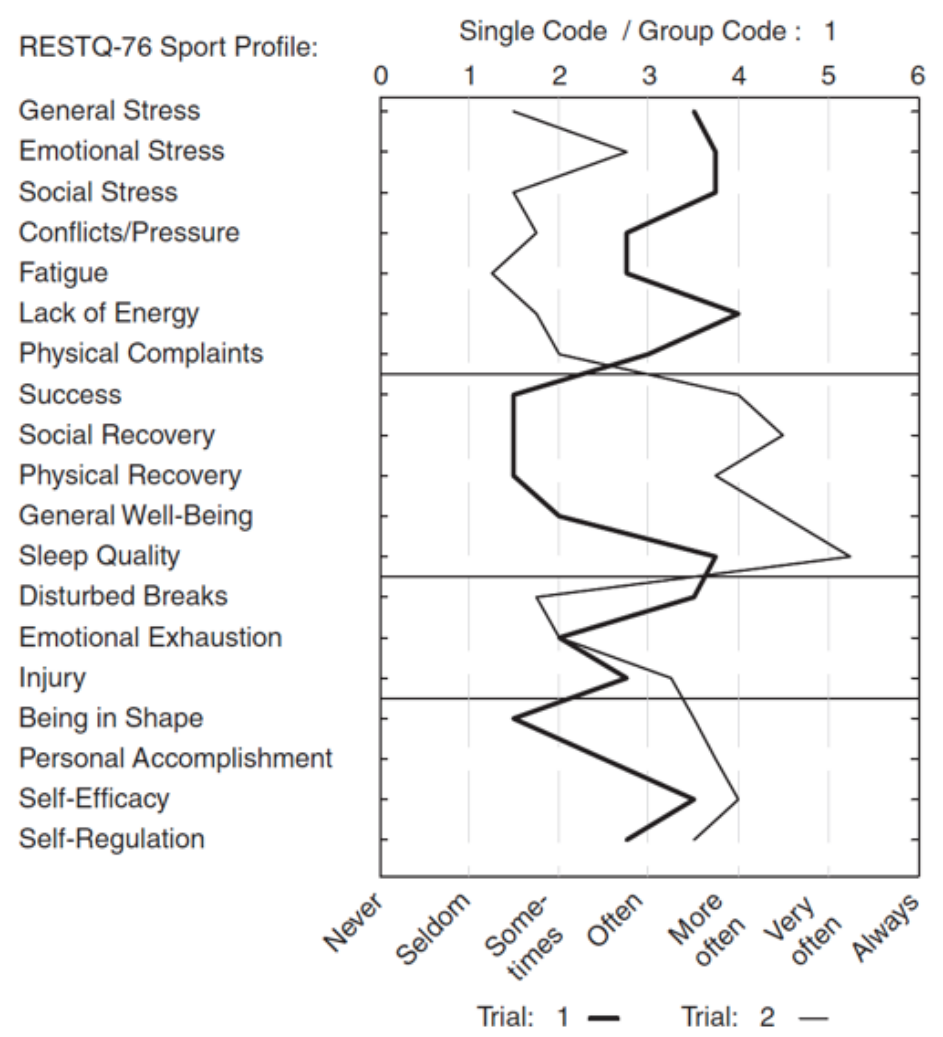

Figure 6. Recovery-Stress Questionnaire for Athletes profile for a male rower at two times of measurement.

Cognitive-behavioral intervention (CBI) utilizes altering mechanisms of some ineffective beliefs and conditioning to intervene with post-traumatic symptoms and comprises of components coming from behavior and cognitive alleviation. Since CBI is utilized in several other stress disorders, for the traumatic episodes, there are particular approaches termed as trauma-focused CBI, such as exposure, cognitive restructuring, and several coping skills, either alone or combined with the other. Majority of trauma-focused CBI types are concise and include weekly sessions of around 60 to 90 minutes. This mechanism can be administered either as a cluster or individual intervention (Vasile, 2014).

A 33-year-old Asian obese individual who had suffered moral injury from false accusation of behavior and reputation began to be aggressive in conversations and the intensity of his anger was managed by lifting heavy weights for several months. Existing and lost weights were measured every month and is tabulated below: 
Table 1

Weight Summary of Existing and Lost Weights per Month

\begin{tabular}{ll}
\hline Monthly weight & Kilos lost every month \\
\hline September 2017-67 kilos & Sept.-Oct. 2017-5 kilos \\
October 2017-62 kilos & Oct.-Nov. 2017-4 kilos \\
November 2017-58 kilos & Nov.-Dec. 2017-1 kilo \\
December 2017-57 kilos & Dec.-Jan. 2018-1 kilo \\
January 2018-56 kilos & Jan.-Feb. 2018-1 kilo \\
February 2018-55 kilos & Feb.-Mar. 2018-2 kilos \\
March 2018-53 kilos & Mar.-Apr. 2018-3 kilos \\
April 2018-50 kilos & total-17 kilos \\
\hline
\end{tabular}

His anger kept on persisting as he recalls his previous encounters with past acquaintances. In order to control his anger, he kept on lifting heavy weights starting September of 2017 to April of 2018. Results of lost weight were shown in Table 1. In computation of his body mass index (BMI), the 33-year-old Asian man went from obese to normal BMI acknowledging a height of 58.27 inches, in duration of eight months. The Exponential Injury Severity Score (EISS) calculation of the 33-year-old Asian man is exhibited below:

Exponential Injury Severity Score Computation:

$$
\begin{aligned}
\text { EISS } & =3^{5-2}+3^{4-2}+3^{3-2} \\
& =3^{3}+3^{2}+3^{1} \\
& =27+9+3 \\
& =39
\end{aligned}
$$

EISS by Interpolation:

$$
\begin{gathered}
5=27 \\
X=39 \\
6=81 \\
\frac{x-5}{1}=\frac{12}{42} \\
x-5=\frac{12(1)}{42} \\
x=0.29+5
\end{gathered}
$$

$x=5.29$ (Severe injury based on Table 2)

Table 2

EISS Calculation According to the AIS Codes

\begin{tabular}{llll}
\hline AIS Codes (A) & $3^{\mathrm{A}-2}(\mathrm{~B})$ & $(\mathrm{C})$ & $(\mathrm{D})$ \\
\hline 1 & $3^{1-2}$ & $3^{-1}$ & 0.3 \\
2 & $3^{2-2}$ & $3^{0}$ & 1 \\
3 & $3^{3-2}$ & $3^{1}$ & 3 \\
4 & $3^{4-2}$ & $3^{2}$ & 9 \\
5 & $3^{5-2}$ & $3^{3}$ & 27 \\
6 & $3^{6-2}$ & $3^{4}$ & 81 \\
\hline
\end{tabular}

Cognitive-behavioral intervention (CBI) served as the approach chosen by the 33-year-old Asian man to mitigate his post-traumatic symptoms of injustice leading to extreme anger exacerbated by abusive words 
resulting to emotional trauma. In order to alleviate his anger, vigorous lifting of weights was performed by the 33-year-old Asian man that resulted to significant weight loss exhibited as normal BMI from obese category, hence, leading back to an excellent and healthy life as shown in Figure 7.

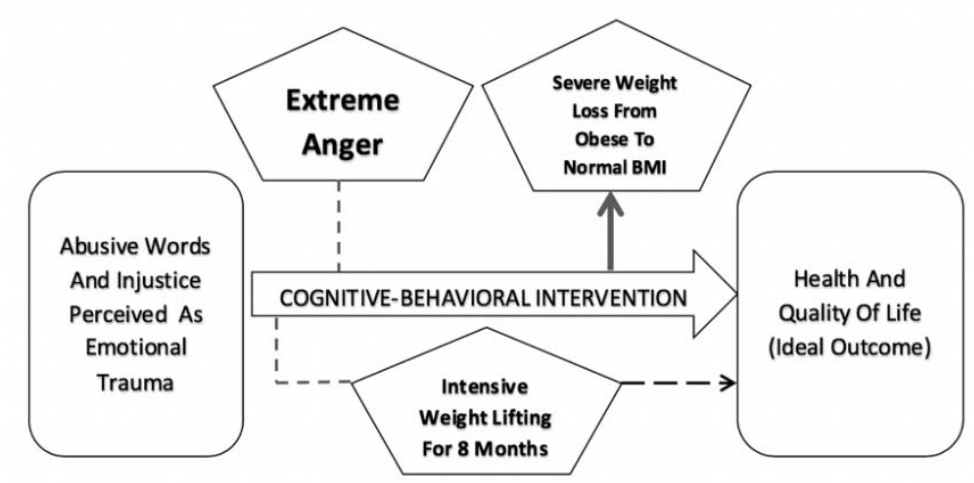

Figure 7. Analytical principle cognitive-behavioral intervention (CBI) aiming for the liberation of emotional trauma subsequent to exposure of emotional trauma.

\section{Conclusion}

Universal Declaration of Human Rights as proclaimed and adopted by United Nations General Assembly visualizes Universal respect promotion to any race, gender, language, or religion seeking for freedom on opportunity and process based on its capability and demands of legal agreement for social welfare. Contract law has two sets of obligations, namely, legal and moral. Legal issues standardize on regulation of promises, while moral obligation handles ethical administration. Furthermore, choice of law can either be substantive or procedural. Heads of damages are applied to substantive issues like medical expenses and lost wages, while quantification of damages are sought for procedural issues that are often related to discovery rules. Procedural issues handle moral obligation involving cases for ethical administration which can be related to emotional trauma problems brought by inducement of anger. Several young elites are driven to sports science for stress intervention. Training has a wide variety of scope tackling and observing same principle out of same study population. Abbreviated Injury Scale (AIS) is the measurement of severity of injuries based on emotional trauma experienced by an individual. Exponential Injury Severity Score (EISS) is a modification tool of AIS by change computation in one body region pertaining to weight reduction. From 67 kilos to 50 kilos body weight loss observed from September 2017 to April 2018, computed EISS exhibited a score of 5.29 indicating a severe trauma experienced by the 33-year-old Asian man. Thus, management of anger can be executed through cognitive-behavior intervention (CBI) as tool for sports medicine in order to promote quality of health and life. Moreover, quantification of damages for procedural concerns of forum shopping can be a procedural choice of law that can be sought for violation of moral obligation as supported by United Nations for universal respect advocacy of international human rights.

\section{References}

Al-Tawil, T. (2013). Damages for breach of contract: Compensation, cost of cure and vindication. Adelaide Law Review, 34(2), 351-377.

Balcombe, L. (2012). Responses of elite athletes to the negative consequences of turning points during and after their sport Careers (Dr. thesis, Griffith University). 
Kamruzzaman, M. D., \& Das, S. K. (2016). The evaluation of human rights: An overview in historical perspective. American Journal of Service Science and Management, 3(2), 5-12.

Kellman, M. (2010). Preventing overtraining in athletes in high-intensity sports and stress/recovery monitoring. Scandinavian Journal of Medicine \& Science in Sports, 20(s2), 95-102.

MacNaughton, G., \& Forman, L. (2014). The value of mainstreaming human rights into health impact assessment. International Journal of Environmental Research and Public Health, 11(10), 10076-10090.

Marshall, B. A. (2012). Reconsidering the proper law of the contract. Melbourne Journal of International Law, 13(1), 505-539.

Sen, A. (2005). Human rights and capabilities. Journal of Human Development, 6(2), 151-166.

Schwartz, A., \& Scott, R. E. (2003). Contract theory and the limits of contract law. The Yale Law of Journal, 113(3), 541-619.

Schafer, H. B. (1999). 3000 Tort law: General. In Encyclopedia of Law \& Economics (pp. 569-596). Hamburg: University of Hamburg.

Taylor, K. L. (2012). Monitoring neuromuscular fatigue in high performance athletes (Dr. thesis, Edith Cowan University).

Venter, R. E. (2008). A model for psychophysiological regeneration of elite team athletes (Ph. D. thesis, Stellenbosch University). Vasile, C. (2014). An analysis of psychological trauma interventions. Social and Behavioral Sciences, 127, 781-785.

Weintraub, R. J. (2007). Choice of law for quantification of damages: A judgment of the house of lords makes a bad rule worse. Texas International Law Journal, 42, 311-322. 